\title{
Chemically Assisted Directed Assembly of Carbon Nanotubes for the Fabrication of Large- Scale Device Arrays
}

George S. Tulevski, * James Hannon, Ali Afzali, Zhihong Chen, Phaedon Avouris and

Cherie R. Kagan

IBM T. J. Watson Research Center, Yorktown Heights, New York 10598

Email: gstulevs@us.ibm.com

\section{Supplemental Materials:}

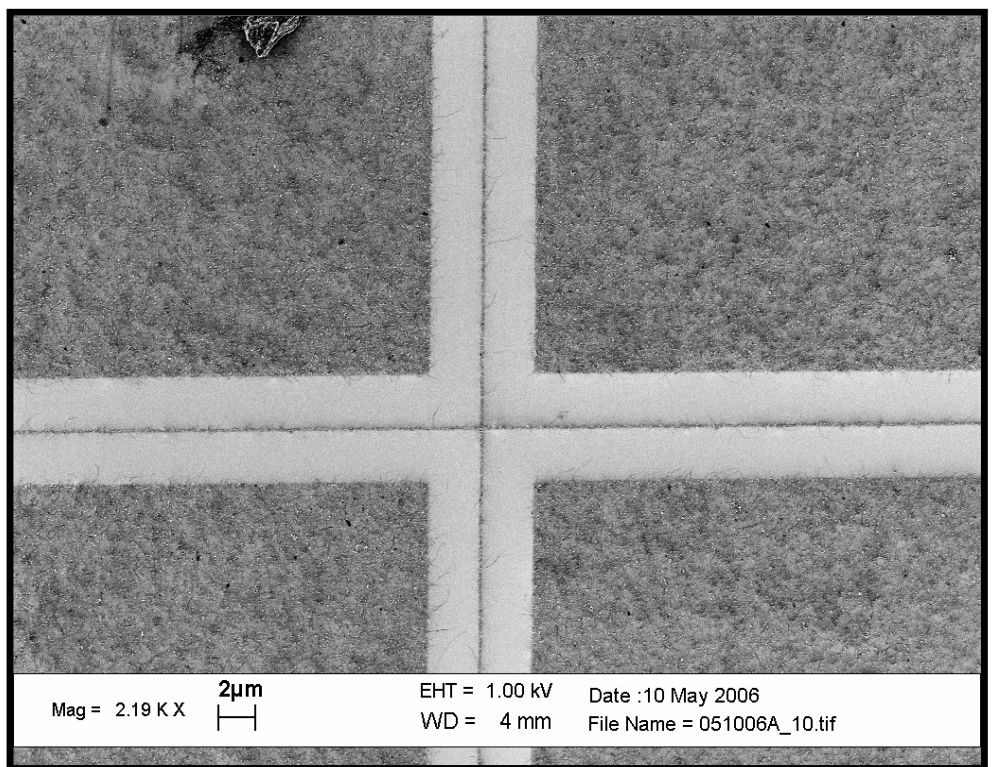

Figure S1: SEM image of an assembly of functionalized SWCNT on an inverted gate stack $\left(\mathrm{HfO}_{2}\right.$ on $\left.\mathrm{SiO}_{2}\right)$. The $\mathrm{HfO}_{2}$ is on a ridge, as opposed to in a trench. The functionalized SWCNTs show selectivity towards the $\mathrm{HfO}_{2}$, yet the degree is lower as the SWCNTs over-hang the ridges and fall into the $\mathrm{SiO}_{2}$ region, which also eliminates any orientation control of the SWCNTs. 


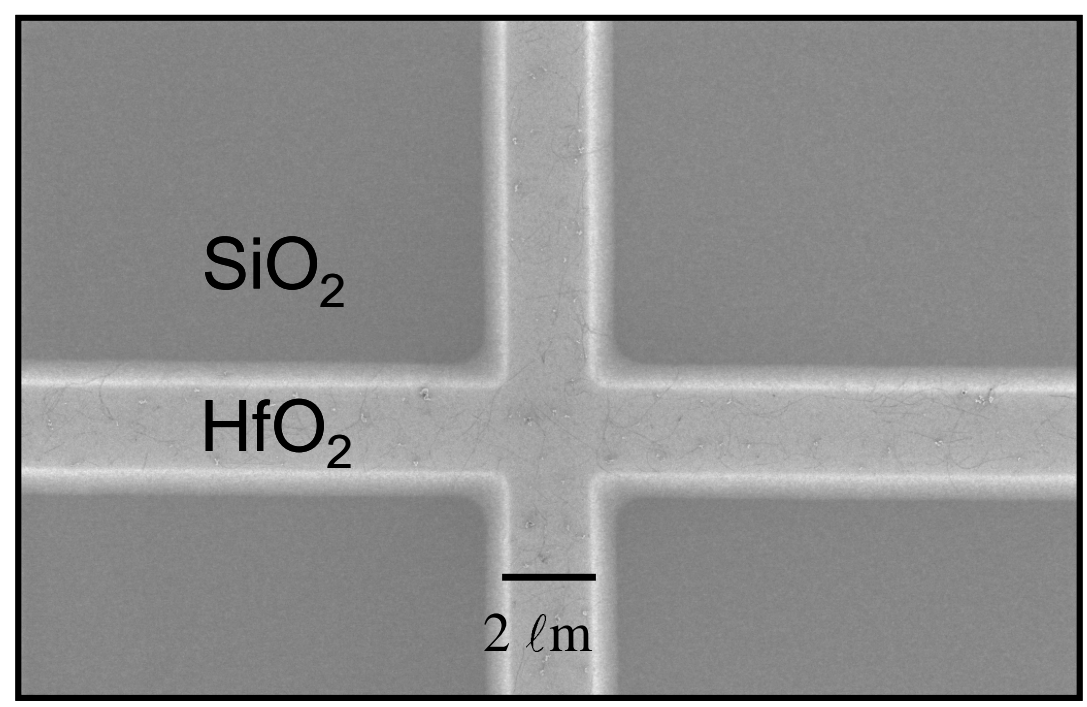

Figure S2: Large-area SEM image of a $2 \ell \mathrm{m} \mathrm{HfO}_{2}$ bottomed trench. The functionalized SWCNT only bind in the trench, and are not found on the $\mathrm{SiO}_{2}$ portion of the patterned surface. 